\title{
Commitment Between Roughness and Crystallite Size in the Vanadium Oxide Thin Film opto-electrochemical Properties
}

\author{
Luís Henrique Cardozo Amorin $^{a \star}{ }^{\mathbb{D}}$, Larissa da Silva Martins, Alexandre Urbano ${ }^{a}$ \\ ${ }^{a}$ Laboratório de Filmes Finos e Materiais, Departamento de Física, Universidade Estadual de \\ Londrina, CEP 86057-970, Londrina, PR, Brasil
}

Received: April 02, 2018; Revised: July 27, 2018; Accepted: October 04, 2018

The $\mathrm{V}_{2} \mathrm{O}_{5}$ thin films has been widely studied because it has application as ionic host in electrochromic and lithium-ion batteries, two technologies that have an intimate connection with sustainability as substitutes for fossil energies and as agents for improving energy efficiency. In electrochromic technology, $\mathrm{V}_{2} \mathrm{O}_{5}$ is applied as a passive electrode due to its high transmittance and small contrast, and its reversibility on electrochemical reactions. To contribute to increase the optical and charge efficiency of $\mathrm{V}_{2} \mathrm{O}_{5}$ thin film passive electrodes, were investigated in this work the influence of the morphological properties, crystallite size and roughness, on the reversible specific charge capacity and the respective optical responses. The films morphological properties were modified by varying their thickness to the nanoscale. The films were deposited by thermal evaporation from powdered $\mathrm{V}_{2} \mathrm{O}_{5}$. The crystallite size and surface roughness were measured respectively by XRD and AFM. The results showed that the charge capacity is directly proportional to the surface roughness and inversely proportional to the crystallite size. The film optical contrast and the nominal transmittance shows to be improved according to their morphological properties. In conclusion, the $\mathrm{V}_{2} \mathrm{O}_{5}$ opto-electrochemical properties can be improved, increasing the efficiency on the light control processes.

Keywords: Thermal evaporation, vanadium oxide, electrochromism, lithium intercalation.

\section{Introduction}

Electrochromic materials have been widely studied, since their inception ${ }^{1}$, considering the characteristics of this material, which might be easily integrated into many scientific and technological applications ${ }^{2-4}$. Nowadays its commercial application focuses on smart windows, which replace curtains in the control of light and heat entering a room that has an intimate connection with sustainability as agents for improving energy efficiency ${ }^{5}$.

Electrochromic devices are similar to a battery; they are composed of two electrodes separated by an ionic electrolyte. They present a difference of electric potential and charge and discharge electronic capacity. The electric current in an electrochromic device is a result of the ionic intercalation of the electrolyte species in the host oxide structure, altering its optical properties. The optical changes arise from the increased ratio between reduced and oxidized species within the electrode and vary according to the amount of intercalated charge, which promotes, for most cathode materials ${ }^{6-10}$, the appearance of states of energy in the form of small polarons.

Electrochromic materials can be classified into three types: 1) active cathodic, 2) active anodic, and 3) the passive (although it does not vary their optical absorption with the ionic intercalation). The fundamental characteristic of an active-type electrochromic material is its ability to modulate the absorption of radiation due to the co-intercalation of electron and ionic species into its electronic and crystallographic

*e-mail: luis.amorin@gmail.com structures respectively. While the cathodic active electrode $\left(\mathrm{WO}_{3}, \mathrm{TiO}_{2}, \mathrm{MoO}_{3}, \mathrm{~V}_{2} \mathrm{O}_{5}\right.$ etc.) darkens when it receives ions and electrons in its structure, the anodic electrode $(\mathrm{NiO}$, $\mathrm{MnO}_{2}, \mathrm{Co}_{3} \mathrm{O}_{4}, \mathrm{~V}_{2} \mathrm{O}_{5}$ etc.) becomes transparent and vice versa as the ions and electrons leave their structures.

An electrochromic device can be constructed in two ways, Figure 1. First, with opposite optical modulation electrodes, one of the anodic type and the other of the cathodic type, which means that while one electrode is clear the other is also and the same two dims together. Second, by changing the anodic electrode to one of the passive type, whose main characteristics are the high transparency and the small optical contrast. All electrochromic component has to be transparent, the electrolyte and the electronic conductor (ITO).

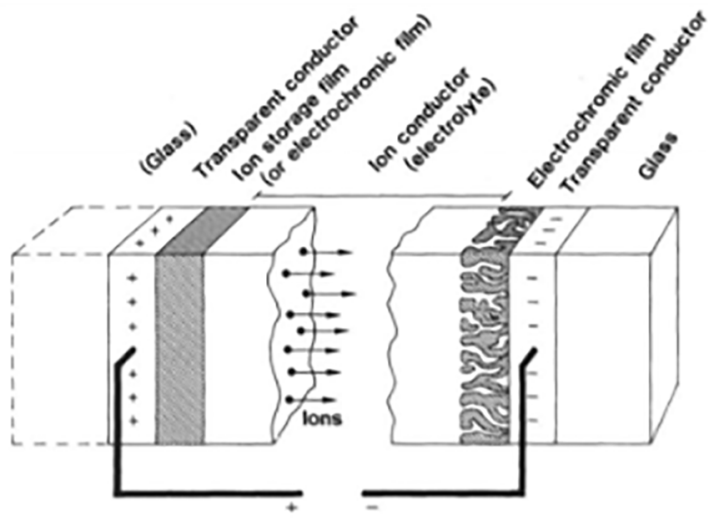

Figure 1. Basic design of an electrochromic device ${ }^{11}$ 
$\mathrm{V}_{2} \mathrm{O}_{5}$ films can be prepared by physical and chemical routes ${ }^{12-15}$. Although physical deposition, such as resistive thermal evaporation, has a high cost when compared to chemical deposition, it offers a better control to the thin film composition, and structural and morphological aspects ${ }^{16,17}$. Thus, the deposition by thermal evaporation is a suitable technique to investigate the influence of the microstructural $\mathrm{V}_{2} \mathrm{O}_{5}$ thin films properties on their electrochemical charge capacity performance and optical behavior ${ }^{18}$.

Several works showed that $\mathrm{V}_{2} \mathrm{O}_{5}$ thin films deposited by physical process with controlled thickness, varying from few hundreds to thousands of nanometers, presented maximum transmittance around $90 \%$ and optical contrast of about $20 \%$. For a passive film integrating a electrochromic device, these values has to be improved ${ }^{19,20}$. With regard to the reversible ion storage capacity, for applications as a rechargeable battery electrode, $\mathrm{V}_{2} \mathrm{O}_{5}$ presents $294 \mathrm{mAhg}^{-1}$ theoretical charge capacity, which value is higher than the electrodes usually used in batteries such as $\mathrm{LiCoO}_{2}(274$ $\mathrm{mAhg}^{-1}$ ), and its electrochemical performance can increases when it is made of nanoparticles ${ }^{21}$.

Film thickness has a great impact on your own stoichiometry, shape, crystallites sizes and orientation and optical properties ${ }^{22},{ }^{23}$. The impact of the thickness on the stoichiometry of the film is due to the variability of oxides that may be formed, which also explains why the optical variations may not follow the Beer Lambert Law ${ }^{24-26}$. The influence of thickness on crystallite size has been related due to shortening of the unit cell parameters ${ }^{27}$, and due to the $\mathrm{V}_{2} \mathrm{O}_{5}$ film doping ${ }^{28}$.

To contribute to increase the efficiency of $\mathrm{V}_{2} \mathrm{O}_{5}$ thin film passive electrodes, that is, a film that exhibit high transmittance with small contrast and high charge capacity, were investigated in this work the influence of the morphological properties, crystallite size and roughness, on its opto-electrochemical performance. The films morphological properties were modified by varying the film thickness to the nanoscale.

\section{Methodology}

Vanadium oxide thin films were deposited by resistive thermal evaporation under high vacuum in an HHV (AUTO 306) system. Glass plates covered with ITO were used as substrates. The pellet $\mathrm{V}_{2} \mathrm{O}_{5}$ powder evaporation source was obtained from SIGMA-ALDRICH, 99.9\%. The glow-discharge was performed to ensure substrate surface cleaning before the depositions. The base pressure was $7.89 \times 10^{-6} \mathrm{mbar}$ and $1.15 \times 10^{-5}$ mbar during deposition. The samples (Figure 2) were thermally treated in an oxidizing atmosphere $\left(\mathrm{O}_{2}\right)$ at $400{ }^{\circ} \mathrm{C}$ by 2 hours.

The films thicknesses were measured indirectly by the calcium $\mathrm{K} \alpha$ intensity attenuation using a portable X-ray fluorescence system (PXRF), whose diagram is shown in

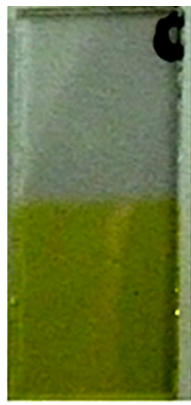

(A)

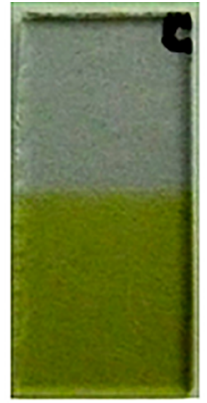

(B)

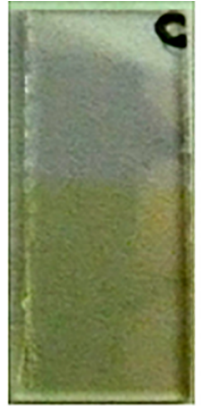

(C)
Figure 2. Samples images of the films studied with different thicknesses after heat treatment.

Figure $3 .{ }^{29}$ Table 1 shows the thickness and surface density against the mass of the evaporating $\mathrm{V}_{2} \mathrm{O}_{5}$ powder.

The $\mathrm{CaK} \alpha$ comes from borosilicate substrate, and the values were shown in Table 1 .

The samples morphology were analyzed by atomic force microscopy (AFM), (Nanosurf), in the intermittent contact mode. Images were acquired covering $30 \times 30 \mu \mathrm{m}^{2}$ with 512 points per line. The RMS (root mean square) was obtained by Gwyddion software. The X-ray diffraction (XRD) measurements were performed on a Bruker D8 diffractometer with $\mathrm{CuK} \alpha$ radiation, $\theta-2 \theta$ geometry, angle range from 18 to $25^{\circ}(2 \theta)$, the step size of $0.05^{\circ}$ and $5 \mathrm{~s}$ for counting time per point. The $\mathrm{X}$-ray tube voltage and current were $40 \mathrm{kV}$ and $40 \mathrm{~mA}$, respectively. The crystallite size (S) was calculated from the (001) peak of the samples, using Scherrer equation:

$$
S=\frac{K \lambda}{\beta_{(2 \theta)} \cos \theta}
$$

where $\mathrm{K}$ is the form factor choose as $0.94{ }^{30}, \lambda$ is the $\mathrm{CuK} \alpha$ wavelength, $\beta_{(2 \theta)}$ is the peak FWHM, and $\theta$ is the diffraction angle, both in radians for the same (hkl) reflection plane. $\beta_{(2 \theta)}$ was estimated using a gaussian function and corrected by the equation 2 , where $\beta_{\text {instrumental }}$ was obtained from silicon polycrystalline standart at the same instrumental configuration.

$$
\beta_{(2 \theta)}=\sqrt{\beta_{\text {measured }}^{2}-\beta_{\text {instrumental }}^{2}}
$$

Opto-electrochemistry measurements were performed in situ in a three-electrode cell using a $632.8 \mathrm{~nm}$ monochromatic laser. The working electrode (WT) was the $\mathrm{ITO} / \mathrm{V}_{2} \mathrm{O}_{5}$, and both the counter electrode (CE) and the reference electrode (RE) are metallic lithium wires. The electrolyte was a solution of lithium perchlorate $\left(\mathrm{LiClO}_{4}\right)$ dissolved in propylene carbonate (PC) at $1.0 \mathrm{~mol} / \mathrm{L}$. Cyclic voltammetry and chronopotentiometry were performed in a potentiostat/ galvanostat (VoltaLab10, Radiometer Analytical). Voltammetry was done within a 2.0 to $3.8 \mathrm{~V}$ potential range and $0.1 \mathrm{mV} / \mathrm{s}$ 


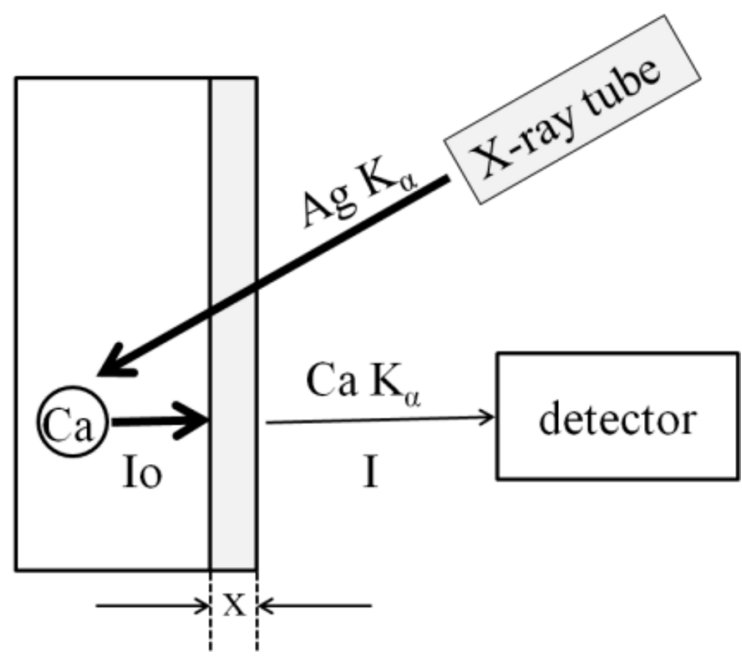

Figure 3. Schematic of the $\mathrm{CaK} \alpha$ attenuation for the film thickness measurement.

Table 1. Thickness of $\mathrm{V}_{2} \mathrm{O}_{5}$ samples calculated by attenuation of the calcium $\mathrm{K} \alpha$ line.

\begin{tabular}{ccccc}
\hline Sample & $\begin{array}{c}\text { Deposited } \\
\text { mass } \\
(\mathrm{mg})\end{array}$ & $\begin{array}{c}\text { Ca-Ka net } \\
\text { area } \\
(\text { arb. unit })\end{array}$ & $\begin{array}{c}\text { Thickness } \\
(\mathrm{nm})\end{array}$ & $\begin{array}{c}\text { Surface } \\
\text { density } \\
\left(\mu \mathrm{g} / \mathrm{cm}^{2}\right)\end{array}$ \\
\hline A & $26 \pm 3$ & 10008 & $50 \pm 7$ & $16.1 \pm 3.3$ \\
B & $56 \pm 3$ & 9081 & $110 \pm 3$ & $36.9 \pm 3.0$ \\
C & $82 \pm 3$ & 8501 & $160 \pm 5$ & $53.7 \pm 3.8$ \\
\hline
\end{tabular}

for the scanning speed. Chronopotentiometry was applied to the cell at $\pm 1 \mu \mathrm{A}$ from 2.0 to $3.8 \mathrm{~V}$.

\section{Results and Discussions}

\subsection{Atomic force microscopy and X-ray diffraction}

Figure 4 shows the AFM images of the $\mathrm{V}_{2} \mathrm{O}_{5}$ films of samples A, B and C. The AFM images show, in the used scale, that the roughness increases as the thickness decreases. The RMS decreased from 13 to 11.2 and to $6.7 \mathrm{~nm}$ for the A, B and C samples respectively (50, 110 and $160 \mathrm{~nm}$ ). It is in agreement with the increase on surface density showed in table 1. It is evident that with the increase of the film thickness, the morphology of the film became more uniform, reducing its surface roughness and increasing its density.

The X-ray diffractograms of the heat treated $\mathrm{V}_{2} \mathrm{O}_{5}$ thin films deposited on the ITO-covered glass substrate are shown in Figure 5. It can be observed, for all samples, a Gaussian like peak centered at $2 \theta=20.17^{\circ}$, and a peak in $2 \theta=21.50^{\circ}$ only for sample $\mathrm{C}$ (high thickness), which are attributed to the orthorhombic phase of $\mathrm{V}_{2} \mathrm{O}_{5}$, with orthorhombic crystal system (Pmmn 59) ${ }^{31,32}$. The decrease in peak intensity is proportional to the decrease in its thickness and the peaks that appear in $2 \theta=24.25^{\circ}$ and $2 \theta=26.23^{\circ}$ refers to the ITO film.
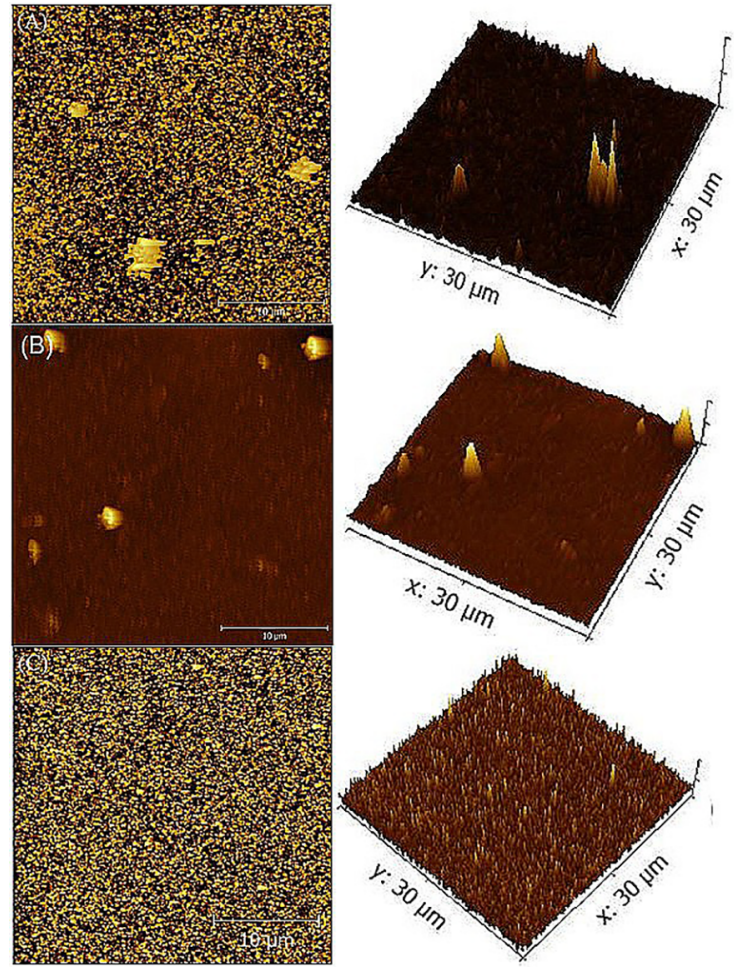

Figure 4. Morphological images of the surface of the films studied with different thicknesses.

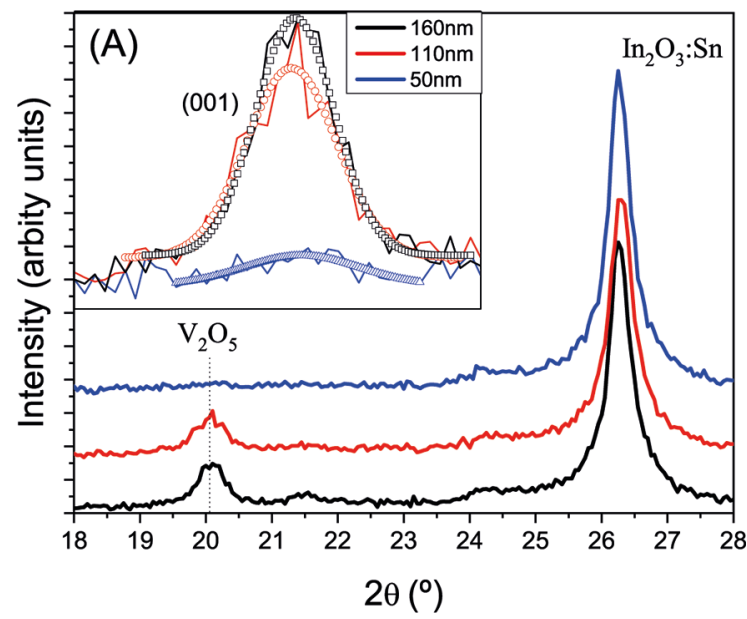

Figure 5. Diffraction of the thermally treated $\mathrm{V}_{2} \mathrm{O}_{5}$ films.

From Scherrer the crystallite size values were $12.2 \mathrm{~nm}, 15.8$ $\mathrm{nm}$ and $18.2 \mathrm{~nm}$, from the lowest to the highest thickness, respectively. Nanocrystalline and continuous films can be understood as consisting of the crystallite volume, and its boundary volume ${ }^{33}$. The excess free volume associated with the crystallite boundaries were estimated using the equation (3) and the values are, $8 \%, 6 \%$ and $5 \%$, respectively to $\mathrm{A}, \mathrm{B}$ and $\mathrm{C}$ samples. It is another indicator that the amorphous phase is higher in A sample (smallest thickness).

$$
\Delta V_{F}=\frac{(L+d / 2)^{2}-L^{2}}{L^{2}}
$$




\subsection{Electrochemical properties}

The films voltammograms present three pairs of current peaks, corresponding to the reduction (intercalation), at potentials of $2.33,3.20$ and $3.41 \mathrm{~V}$, and oxidation (deintercalation) at 2.64, 3.23 and $3.44 \mathrm{~V}$ (vs. $\mathrm{Li}^{2} \mathrm{Li}^{+}$). The peaks can be attributed to different phase transitions of $\mathrm{V}_{2} \mathrm{O}_{5}$ , due to the weak van der Waals forces between the adjacent layers, that are showed in the Figure $6^{13,34,35}$.

Chronopotentiometry shows that the normalized amount of intercalated charge, and reversibly deintercalated, is higher for the thinner film (Figure 7).

The transmittance monitoring with $632.80 \mathrm{~nm}$ light showed the effect of double monochromatic coloration, whose maximum optical absorption occurs as the percentage of $\mathrm{V}^{+4}$ and $\mathrm{V}^{+5}$ is of $50 \%$, since the small polaron center needs the pair to exist. The double spectral coloration also occurs in the film and will be shown below. With the intercalation of lithium ions in the film, the vanadium valence state changes from +5 to +4 reversely according the equation 4 .

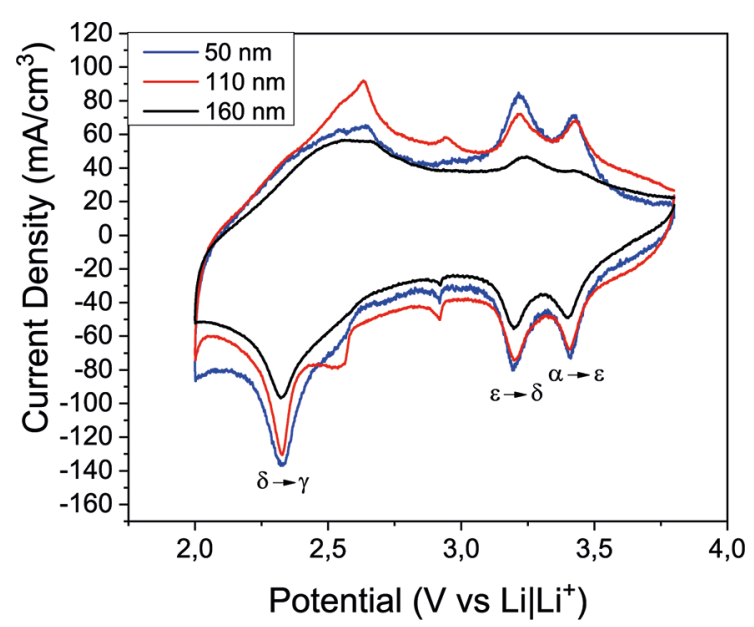

Figure 6. Voltammograms for $\mathrm{V}_{2} \mathrm{O}_{5}$ thin films with different thicknesses, showed the phases transitions.

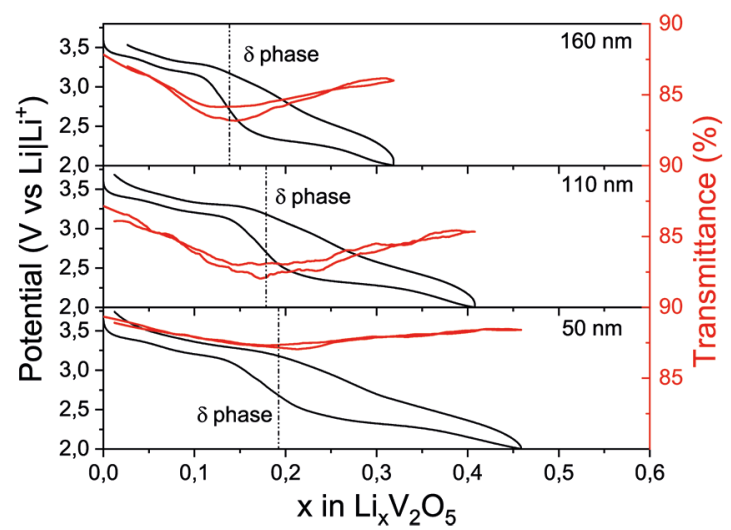

Figure 7. Potential of the cell (black line) and optical transmittance (red line) versus the stoichiometry of $\mathrm{Li}^{+}$intercalated in the films of vanadium oxide.

$$
V_{2}^{+5} \mathrm{O}_{5}^{-2}+x e^{-}+x L i^{+} \underset{\text { oxidation }}{\stackrel{\text { reduction }}{\rightleftarrows}} L i_{x}^{+}\left[V_{2-x}^{+5} V_{x}^{+4}\right] O_{5}^{-2}
$$

In the intercalation process, while lithium ions occupy crystallographic sites, or structural defects, the electrons populate the V3d band causing increase on gap energy and the centers of color absorption (Figure 8) ${ }^{11,36}$.

For high energy photons, $\mathrm{E}>2.0 \mathrm{eV}$, the optical absorption occurs due to the interband electronic transition, $\mathrm{O} 2 \mathrm{p}$ to $\mathrm{V} 3 \mathrm{~d}$ (split). At low energies, $\mathrm{E}<2.0 \mathrm{eV}$, absorption occurs due to small polarons absorption that is the electron hopping between two different vanadium oxidation state ions (electrons going from $\mathrm{V}^{+4}$ to $\mathrm{V}^{+5}$ ). The spectrophotometric curves showed in Figure 9 clearly shows these two phenomena separated by an isosbestic point ${ }^{37}$. While in high energies the absorption increases, in low it decreases and vice versa, as electrode is intercalated or deintercalated. On the inset is showed the inverse behavior on transmittance between high energy and low energy photons. In another paper, a more detailed investigation of double coloration electrochromism will be shown.

In Figure 10 (a) and (b) are shown the correlation between crystallite size, roughness, and the specific charge

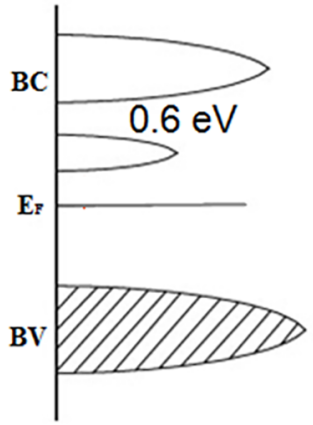

(a)

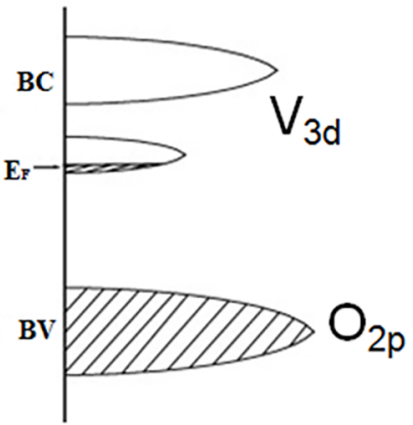

(b)
Figure 8. Banding structure scheme for non-intercalated V2O5 (a) and intercalated (b) [Adapted from $\mathrm{Wu}$ et al. ${ }^{16}$ ].

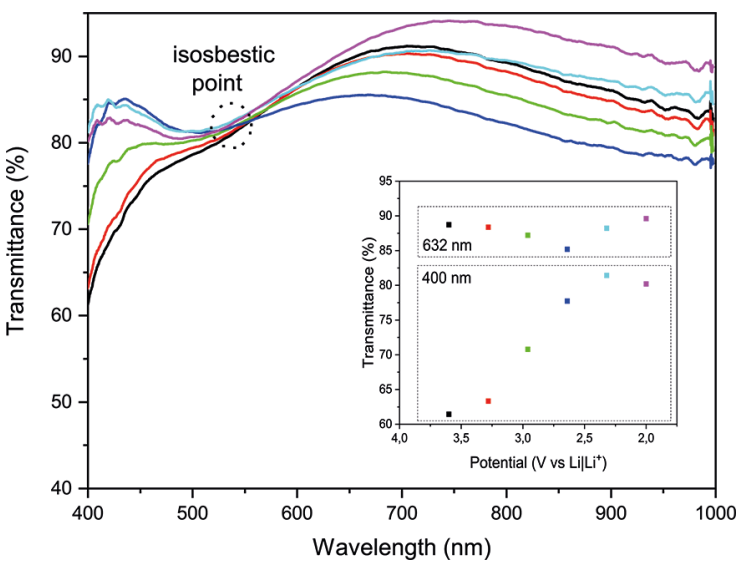

Figure 9.Transmittance as a function of wavelength during the ionic intercalation process (Inset: Transmittance as a function of potential showing regions of optical absorption for blue light (400 $\mathrm{nm})$ and red light $(632 \mathrm{~nm})$ ). 

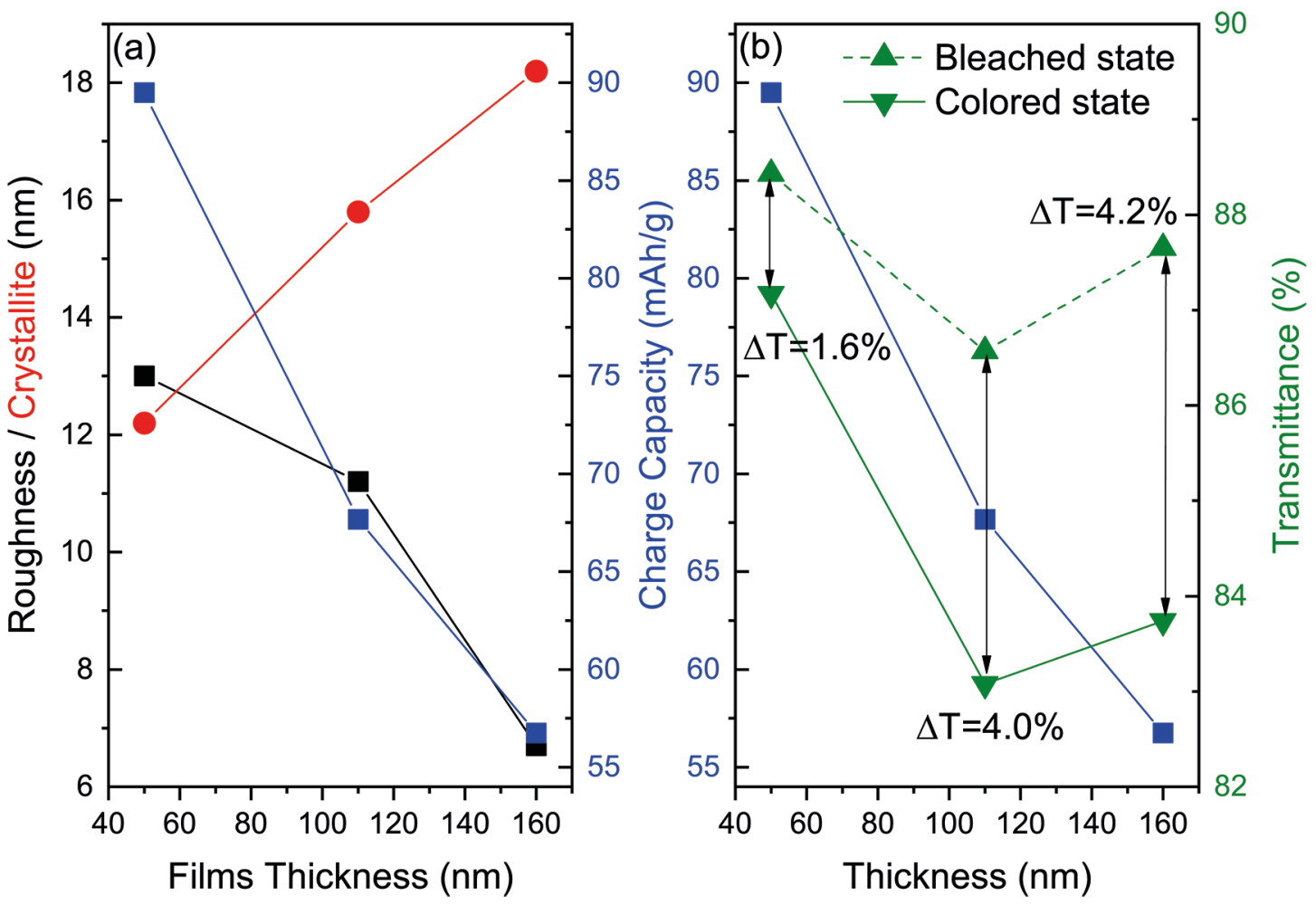

Figure 10. (a) The correlation between the crystallite size, the roughness, and the charge capacity, versus the thickness of the films. (b) The transmittance, in bleached and dark states versus the film thickness.

capacity, versus the films thicknesses. While the specific charge capacity is linearly dependent on the roughness, it is inversely proportional to the crystallite size. As the thickness decreases the transmittance naturally increases, but the contrast percentage has also been shown to be dependent mainly on the crystallite size.

\section{Conclusion}

In this work the influence of the morphological properties, crystallite size and roughness, on the reversible charge capacity and the respective optical responses were investigated. The films morphological properties were modified by varying their thickness to the nanoscale. The electrochemical experiments showed that the specific charge capacity is directly proportional to the surface roughness and inversely proportional to the crystallite size. With the increase of the film thickness, the morphology of the film became more uniform, reducing its surface roughness and increasing its density. The film optical contrast and the nominal transmittance shows to be improved according to their morphological properties. There are arguments to conclude that the optimization of the opto-electrochemical properties of $\mathrm{V}_{2} \mathrm{O}_{5}$ thin films can be achieved by decreasing the size of its crystallites and increasing their roughness, optimizing and increasing the efficiency on the light control processes.

\section{Acknowledgements}

To Laboratory of Nanostructured Films and Spectroscopy at São Paulo State University (UNESP), campus in Presidente Prudente, for the measurements of atomic force microscopy. To the Multi-user Laboratory of the IFGW at UNICAMP, for the measurements of XRD and Caroline Amorin by the graphics editing. CAPES and CNPq for financial support.

Conflicts of Interest: The authors declare that they have no conflicts of interest.

\section{References}

1. Deb SK. A Novel Electrophotographic System. Applied Optics. 1969;8(Suppl 1):192-195.

2. Mjejri I, Rougier A, Gaudon M. Low-Cost and Facile Synthesis of the Vanadium Oxides $\mathrm{V}_{2} \mathrm{O}_{3}, \mathrm{VO}_{2}$, and $\mathrm{V}_{2} \mathrm{O}_{5}$ and Their Magnetic, Thermochromic and Electrochromic Properties. Inorgic Chemistry. 2017;56(3):1734-1741.

3. Liang X, Gao G, Liu Y, Ge Z, Leng P, Wu G. Carbon nanotubes/ vanadium oxide composites as cathode materials for lithiumion batteries. Journal of Sol-Gel Science and Technology. 2017;82(1):224-232. 
4. Bera B, Esther ACM, Dey A, Mukhopadhyay AK. Structural, optical and electrical properties of $\mathrm{V}_{2} \mathrm{O}_{5}$ xerogel thin films. Indian Journal of Physics. 2016;90(6):687-692.

5. Azevedo CF, Balboni RDC, Cholant CM, Moura EA, Lemos RMJ, Pawlicka A, et al. New thin films of $\mathrm{NiO}$ doped with $\mathrm{V}_{2} \mathrm{O}_{5}$ for electrochromic applications. Journal of Physics and Chemistry of Solids. 2017;110:30-35.

6. Dinh NN, Quyen NM, Chung DN, Zikova M, Truong VV. Highlyefficient electrochromic performance of nanostructured $\mathrm{TiO}_{2}$ films made by doctor blade technique. Solar Energy Materials and Solar Cells. 2011;95(2):618-623.

7. Zhou D, Xie D, Xia X, Wang X, Gu C, Tu J.All-solid-state electrochromic devices based on $\mathrm{WO}_{3} \mid \mathrm{NiO}$ films: material developments and future applications. Science China Chemistry. 2017;60(1):3-12.

8. Barawi M, De Trizio L, Giannuzzi R, Veramonti G, Manna L, Manca M. Dual Band Electrochromic Devices Based on Nb-Doped $\mathrm{TiO}_{2}$ Nanocrystalline Electrodes. ACS Nano. 2017;11(4):3576-3584.

9. Bogati, S.; Georg, A.; Graf, W. Photoelectrochromic Devices Based on Sputtered WO3 and TiO2 Films. Sol. Energy Mater. Sol. Cells 2017, 163 (November 2016), 170-177.

10. Ivanova T, Harizanova A. Characterization of $\mathrm{TiO}_{2}$ and $\mathrm{TiO}_{2}-\mathrm{MnO}$ oxides prepared by sol-gel method. Solid State Ionics. $2001 ; 138$ (34):227-232.

11. Granqvist CG. Handbook of Inorganic Electrochromic Materials. Amsterdam: Elsevier; 2002.

12. Öksüzoglu RM, Bilgiç P, Yildirim M, Deniz O. Influence of postannealing on electrical, structural and optical properties of vanadium oxide thin films. Optics \& Laser Technology. 2013;48:102-109.

13. TalledoA, Granqvist CG. Electrochromic vanadium-pentoxide-based films: Structural, electrochemical, and optical properties. Journal of Applied Physics. 1995;77(9):4655-4666.

14. Hanlon TJ, Walker RE, Coath JA, Richardson MA. Comparison between vanadium dioxide coatings on glass produced by sputtering, alkoxide and aqueous sol-gel methods. Thin Solid Films. 2002;405(12):234-237.

15. osurdo M, Barreca D, Bruno G, Tondello E. Spectroscopic ellipsometry investigation of V2O5 nanocrystalline thin films. Thin Solid Films. 2001;384(1):58-64.

16. Wu G, Du K, Xia C, Kun X, Shen J, Zhou B, et al. Optical absorption edge evolution of vanadium pentoxide films during lithium intercalation. Thin Solid Films. 2005;485(1-2):284-289.

17. Cheng W. Photodeposition of Electrochromic Metal Oxide Films. Chem. 2018;4(4):659-660.

18. Raj, P. D.; Gupta, S.; Sridharan, M. Influence of the Crystalline Nature of Growing Surface on the Properties of Vanadium Pentoxide Thin Films. Ceram. Int. 2017, 43 (12), 9401-9407.

19. Talledo A, Andersson AM, Granqvist CG. Electrochemically lithiated V2O5 films: An optically passive ion storage for transparent electrochromic devices. Journal of Materials Research. 1990;56:12531256.

20. Ottaviano L, Pennisi A, Simone F, Salvi AM. RF sputtered electrochromic $\mathrm{V}_{2} \mathrm{O}_{5}$ films. Optical Materials. 2004;27(2):307-313.

21. Yao J, Li Y, Massé RC, Uchaker E, Cao G. Revitalized interest in vanadium pentoxide as cathode material for lithium-ion batteries and beyond. Energy Storage Materials. 2018;11:205-259.
22. Singh, P.; Kaur, D. Influence of Film Thickness on Texture and Electrical and Optical Properties of Room Temperature Deposited Nanocrystalline V2O5 Thin Films. J. Appl. Phys. 2008, 103(4).

23. Ramana CV, Smith RJ, Hussain OM. Grain size effects on the optical characteristics of pulsed-laser deposited vanadium oxide thin films. Physica Status Solidia. 2003;199(1):R4-R6.

24. Krishna MG, Bhattacharya AK. Effect of thickness on the optical absorption edge of sputtered vanadium oxide films. Materials Science and Engineering: B. 1997;49(2):166-171.

25. Huang X, Rui X, Hng HH, Yan Q. Vanadium Pentoxide-Based Cathode Materials for Lithium-Ion Batteries: Morphology Control, Carbon Hybridization, and Cation Doping. Particle \& Particle Systems Characterization. 2015;32(3):276-294.

26. Atuchin VV, Kochubey VA, Pokrovsky LD, Kruchinin VN, Ramana $\mathrm{CV}$. Effects of process parameters on the optical constants of highly textured V2O5 thin films. Optics and Spectroscopy. 2014;117(3):423427.

27. Sta I, Jlassi M, Kandyla M, Hajji M, Koralli P, Allagui R, et al. Hydrogen sensing by sol-gel grown $\mathrm{NiO}$ and $\mathrm{NiO}: \mathrm{Li}$ thin films. Journal of Alloys and Compounds. 2015;626:87-92.

28. Patil CE, Tarwal NL, Jadhav PR, Shinde PS, Deshmukh HP, Karanjkar $\mathrm{MM}$, et al. Electrochromic performance of the mixed $\mathrm{V}_{2} \mathrm{O}_{5}-\mathrm{WO}_{3}$ thin films synthesized by pulsed spray pyrolysis technique. Current Applied Physics. 2014;14(3):389-395.

29. Lopes F, Amorin LHC, Martins LS, Urbano A, Appoloni CR, Cesareo R. Thickness Measurement of V2O5 Nanometric Thin Films Using a Portable XRF. Journal of Spectroscopy. 2016;2016:9509043.

30. Culllity BD, Stock SR. Elements of X-Ray Diffraction. 3rd ed. New York: Pearson; 2001.

31. Benmoussa M, Ibnouelghazi E, Bennouna A, Ameziane EL. Structural, electrical and optical properties of sputtered vanadium pentoxide thin films. Thin Solid Films. 1995;265(1-2):22-28.

32. Scarminio J, Catarini PR, Urbano A, Gelamo RV, Rouxinol FP, de Moraes MAB. Li diffusion and electrochromism in amorphous and crystalline vanadium oxide thin film electrodes. Journal of the Brazilian Chemical Society. 2008;19(4):788-794.

33. Banerjee R, Sperling EA, Thompson GB, Fraser HL, Bose S, Ayyub P. Lattice expansion in nanocrystalline niobium thin films. Applied Physic Letters. 2003;822(4):4250-4252.

34. Rao KJ, Pecquenard B, Gies A, Levasseur A, Etourneau J. Structural and electrochemical behaviour of sputtered vanadium oxide films: oxygen non-stoichiometry and lithium ion sequestration. Bulletin of Materials Science. 2006;29(5):535-546.

35. Delmas C, Cognac-Auradou H, Cocciantelli JM, Ménétrier M, Doumerc JP. The $\mathrm{Li}_{\mathrm{\gamma}} \mathrm{V}_{2} \mathrm{O}_{5}$ system: An overview of the structure modifications induced by the lithium intercalation. Solid State Ionics. 1994;69(3-4):257-264.

36. Granqvist CG, Green S, Niklasson GA, Mlyuka NR, von Kræmer S, Georén P. Advances in chromogenic materials and devices. Thin Solid Films. 2010;518(11):3046-3053.

37. Martins LS. Investigação das propriedades estruturais e óticas de filmes finos e nanoestruturados de óxido de vanádio depositados por feixe de elétrons. [Dissertation]. Londrina: Londrina State University; 2012. 69 p. 